Original Research Paper

\title{
Budidaya Dan Olahan Jamur Tiram Sebagai Penggerak Panti Asuhan Pada Masa Pandemi Covid-19
}

\author{
Narita Amni Rosadi ${ }^{*}$, Baiq Dewi Lita Andiana ${ }^{2}$, Mimi Cahayani ${ }^{2}$ \\ ${ }^{\text {I} P r o g r a m ~ S t u d i ~ A g r i b i s n i s, ~ F a k u l t a s ~ P e r t a n i a n, ~ U n i v e r s i t a s ~ I s l a m ~ A l-A z h a r ~ M a t a r a m, ~ N u s a ~ T e n g g a r a ~ B a r a t, ~ I n d o n e s i a ~}$ \\ ${ }^{2}$ Program Studi Akuntansi, Fakultas Ekonomi, Universitas Islam Al-Azhar Mataram, Nusa Tenggara Barat, Indonesia
}

https://doi.org/10.29303/jpmpi.v3i2.626

Sitasi: Rosadi, N. A., Andiani, B. D. L., \& Cahyani, M. (2021). Budidaya Dan Olahan Jamur Tiram Sebagai Penggerak Panti Asuhan Pada Masa Pandemi Covid-19. Jurnal Pengabdian Magister Pendidikan IPA, 4(1)

\author{
Article history \\ Received: 05 Desember 2020 \\ Revised: 30 Desember 2020 \\ Accepted: 09 Februari 2021 \\ *Corresponding Author: Narita \\ Amni Rosadi, Program Studi \\ Agribisnis, Fakultas Pertanian, \\ Universitas Islam Al-Azhar \\ Mataram, Nusa Tenggara Barat, \\ Indonesia; \\ Email: \\ naritaamnirosadi13@gmail.com
}

\section{Pendahuluan}

Sektor pertanian memiliki peranan cukup penting untuk menunjang kemajuan pembangunan ekonomi khususnya untuk para petani dan masyarakat umumnya. Komoditi yang dihasilkan oleh pertanian dapat dijadikan sebagai sumber kehidupan bagi masyarakat. Sentuhan teknologi pertanian dalam usaha tani sangat dibutuhkan untuk meningkatkan hasil produksi dan kualitas sehingga ketahanan pangan tercapai serta menunjang

\begin{abstract}
Pengabdian pada masyarakat merupakan kegiatan pengamalan ilmu pengetahuan kepada masyarakat dalam kegiatan ini adalah pada siswa/siswi di panti asuhan Hidayaturrahman. Panti asuhan ini lokasinya di Desa Turide Timur Kecamatan Sandubaya Kota Mataram. Kegiatan ini merupakan kolaborasi dari dosen Fakultas Pertanian dan Fakultas Ekonomi Universitas Islam Al-Azhar. Dalam kegiatan Pengabdian ini para dosen pada Fakultas Pertanian dan fakultas Ekonomi Universitas Islam Al-azhar Mataram berbagi ilmu kepada siswa/siswi tentang bagaimana membudidayakan jamur tiram secara berkualitas dengan hasil yang maksimal. Hasil budidaya ini juga kami bantu untuk bisa diolah dengan memberikan skill cara pengolahan jamur tiram sehingga bisa menjadi produk yang bernilai ekonomi tinggi yaitu berupa keripik jamur crispy dan nugget yang kedepannya diharapkan dapat menjadi sumber perekonomian siswa/siswi. Pada tahap berikutnya kami memberikan pengetahuan tentang cara pembukuan sederhana supaya hasil penjualan dari jamur dan olahan jamur dapat diketahui dan tercatat rapi. Metode dalam penyampaian materi ini yaitu "Discussion and Coaching in action". Metode ini diharapkan mampu menumbuhkan minat belajar siswa/siswi panti asuhan sehingga yang diberikan terserap dengan maksimal. Tujuan dari penelitian ini Penk menumbuhkembangkan Budidaya dan Olahan Jamur Tiram Sebagai Penggerak Panti Asuhan pada masa Pandemi adalah solusi yang ditawarkan dalam gerakan berbasis sumberdaya lokal dan pendapatan ekonomi di masa pandemi Covid-19.
\end{abstract}

Keywords: Program Kreativitas Mahasiswa (PKM); Budidaya jamur tiram; Panti asuhan Hidayaturrahman.

pengembangan kemajuan sistem agribisnis Indonesia (BPS, 2013).

Kegiatan usaha terutama berbasis wilayah merupakan kegiatan utama masyarakat. Kegiatan ini merupakan penggerak ekonomi masyarakat baik di Kota maupun di desa. Kecamatan Turida dibagi menjadi dua yaitu turida Barat dan selatan. Jumlah penduduk di kecamatan turida sangat padat. Ratarata penduduknya mencari sumber kehidupan dari berniaga.

Di Turida Selatan terdapat satu panti asuhan, namanya panti asuhan Hidayaturrahman. 
Panti ini memiliki aktivitas usaha agribisnis budidaya jamur tiram. Usaha yang ini dirintis sejak tahun 2017 sampai sekarang. Melihat dari keadaan lingkungan, peluang untuk mengembangkan jamur tiram sangat cocok mendukung syarat tumbuh jamur tiram. Produksi jamur tiram di panti asuhan Hidayaturrahman kecamatan Turida sangat bepotensi untuk dikeembangkan karena nilai ekonomi yang sangat tinggi, jamur tiram dapat diolah menjadi produk olahan kering tidak hanya dikonsumsi langsung menjadi tumis jamur. Dapat diolah juga menjadi produk kering seperti jamur crispy untuk makan ringan yang sehat bagi keluarga. Jamur merupakan usaha yang mudah dikembangkan dan modal nya bisa dijangkau (Agustina, 2014).

Budidaya jamur tiram dapat dipanen berkali-kali dan bisa bertahap. Berbagai media tumbuh yang dapat digunakan untuk budidaya jamur tiram antara lain kardus dan serbuk gergaji (Enjo, 2015). Selain dengan serbuk gergaji, media tanam dapat juga terbuat dari campuran jerami dan serbuk gergaji Nurul hariadi et al., 2013). Dari hasil analisis usahatani ini jamur tiram prospek bila dikembangkan (Retno et al., 2017). Ada beberapa jenis olahan jamur tiram yang dapat dikembangkan untuk kemandirian masyarakat antara lain dapat dijadikan jamur Crispy dan penyedap alami jamur (Zulfarina et al., 2019).

Adapun peserta program kegiatan ini terdiri dari satu mitra. Dimana mitra tersebut adalah masyarakat yang terlibat dalam panti asuhan di Turida Selatan Kecamatan Sandubaya Kota Mataram. Anak-anak yatim yang ada di panti asuhan ini membudidaya jamur tiram dengan kapasitas 1000 baglog jamur.mereka ingin belajar berwirausaha agar lebih sejahtera.

Di panti asuhan Hidayaturrahman ini khusus anak-anak yatim yang terlibat didalamnya, selama ini belum banyak yang diberdayakan dan sebelumnya bergabung dalam komunitas mana pun, dengan adanya mitra ini akan meningkatnya keterampilan anak panti sehingga kesejahteraan meningkat.

\section{Metode}

Untuk merencanakan dan melaksanakan pengembangan Budidaya Dan Olahan Jamur Tiram Sebagai Penggerak Panti Asuhan Pada Masa
Pandemi, dibutuhkan tahapan kegiatan sebagai berikut:

1) Persiapan yang meliputi:

a. pengumpulan informasi tentang sumber daya manusia (SDM) mitra

b. Pertemuan dengan tim fasilitator pengajar di Unizar yang akan memberi pelatihan sesuai dengan bidang ilmu.

c. Pemberian sosialisasi materi tentang budidaya jamur tiram dengan prosedur operasional yang tepat

d. pemberian sosialisasi materi tentang olahan jamur tiram menjadi jamur crispy dan nugget

e. pemberian sosialisasi materi tentang olahan jamur tiram menjadi jamur crispy dan nugget tentang akuntansi sederhana usaha jamur tiram dan nilai ekonominya

f. Pemberian praktek tentang perawatan jamur tiram, olahan jamur crispy dan nugget dan cara menginput pembukuannya.

2) Sosialisasi.

Menyampaikan maksud dan tujuan kegiatan dan membuat kesepakatan awal rencana tindak lanjut yang akan dilakukan. Kegiatan sosialisasi dilakukan terhadap kelompok sasaran dan pemuka masyarakat serta petugas pelaksana instansi terkait.

Ada beberapa konsep yang dapat diterapkan dalam pemanfaatan lahan pekarangan, yaitu sebagai berikut:

1. Kemandirian panti asuhan untuk mendapatkan dan tambahan dalam sektor kewirausahaan di saat pandemi Covid-19.

2. Tambahan Keterampilan dalam pangan olahan agar peningkatan pendapatan Usaha jamur tiram.

3. Peningkatan pengetahuan untuk pembukuan sederhana.

\section{Hasil dan Pembahasan}

Kegiatan pengabdian masyarakat ini dengan judul Budidaya Dan Olahan Jamur Tiram Sebagai Penggerak Panti Asuhan Pada Masa Pandemi. Di Desa Turida Timur Kecamatan sandubaya Kota Mataram berjalan dengan lancar. Pemilik Panti Asuhan menyiapkan tempat dan mengkoordinir peserta. Peserta penyuluhan merupakan Ustadz pondok dan siswa/siswi panti 
asuhan dan Mahasiswa Fakultas pertanian dan ekonomi. Penyuluhan ini dilakukan pada 6 Desember 2020. Gambar kumbung budidaya jamur tiram berkapasitas 1000 baglog (Gambar 1).

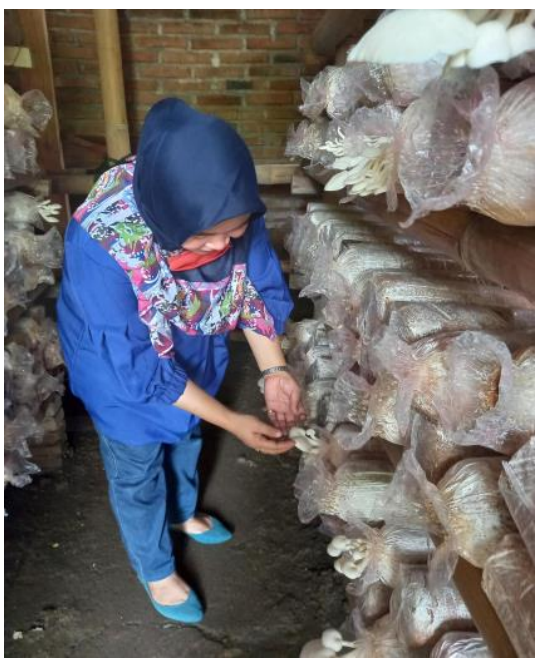

Gambar 1. Kumbung Jamur

Materi pertama disampaikan tentang bagaimana cara budidaya jamur tiram secara baik dan dengan pemeliharaan yang baik pula. Berdasar pengalaman di paparkan bagaimana cara mengolah jamur tiram menjadi jamur Crispy dan Nugget. Selain itu dijelaskan juga limbah berok dapat dipakai sebagai media tanam untuk cabe, tomat dan tanaman lainnya sehingga menambah hasil dari usahatani jamur tiram. materi sosialisasi pertama disampaikan dari fakultas pertanian setelah itu materi sosialisasi kedua disampaikan oleh tim fakultas ekonomi yang membahas tentang pembuatan pembukuan akuntansi sederhana untuk usahatani jamur agar lebih mudah mengetahui keuntungan bersih dari usaha tersebut (Gambar 2, 3 dan 4).

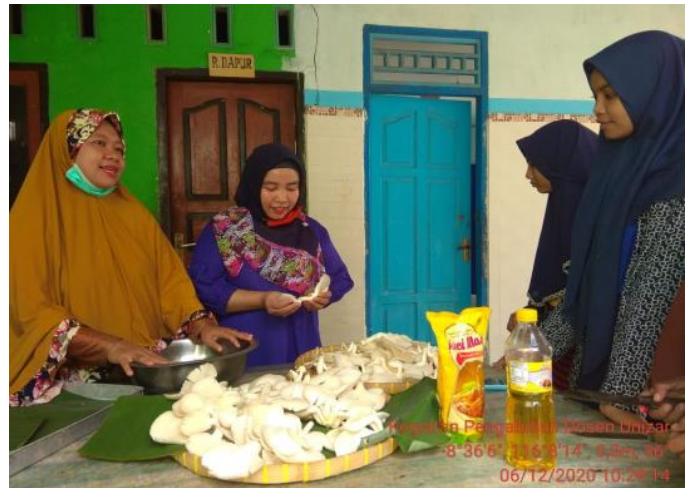

Gambar 2. Penjelasan tentang bagaimana cara merawat jamur

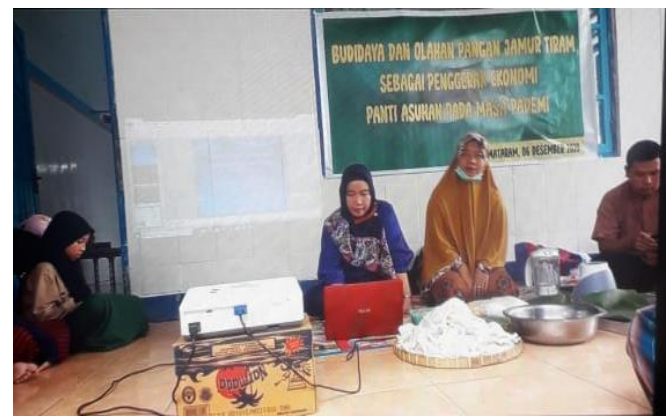

Gambar 3. Penyampaian materi sosialisasi

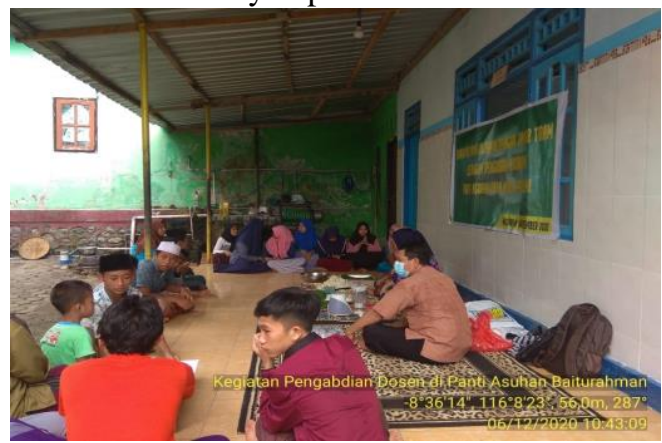

Gambar 4. Peserta pengabdian masyarakat

Tahap kedua dilanjutkan dengan praktek langsung bagaimana cara membuat olahan jamur tiram menjadi jamur Crispy dan Nugget. Pertamatama bahan yang disiapkan untuk pembuatan jamur crispy adalah: tepung bumbu $1 \mathrm{~kg}$, jamur tiram yang sudah disuir-suir satu $\mathrm{kg}$, dan air langkah selanjutnya tepung dan air dicampur untuk membuat adonan basah, dan setelah dibalurkan ke tepung bumbu yang kering hingga merata setelah itu digoreng dengan minyak. Resep kedua yaitu membuat nugget jamur dengan bahan-bahan yang digunakan adalah $1 / 4$ jamur tiram yang sudah diblender dengan bumbu 4 siung bawang putih, 4 sendok tepung dan 1 sendok teh garam (Gambar $8,9,10)$.

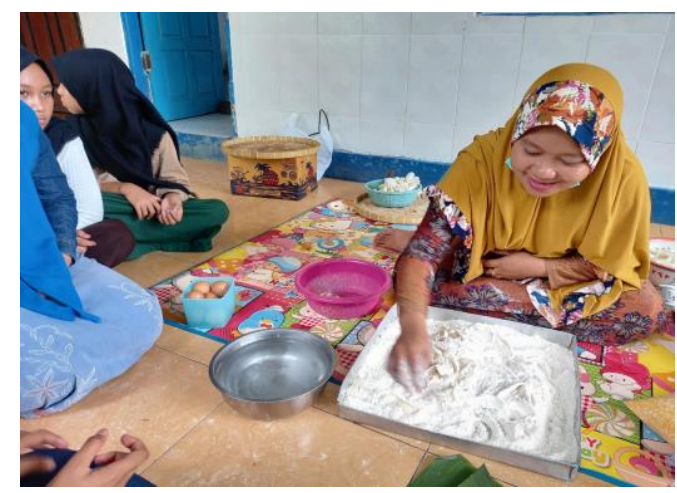

Gambar 5. Pembuatan Jamur crispy 


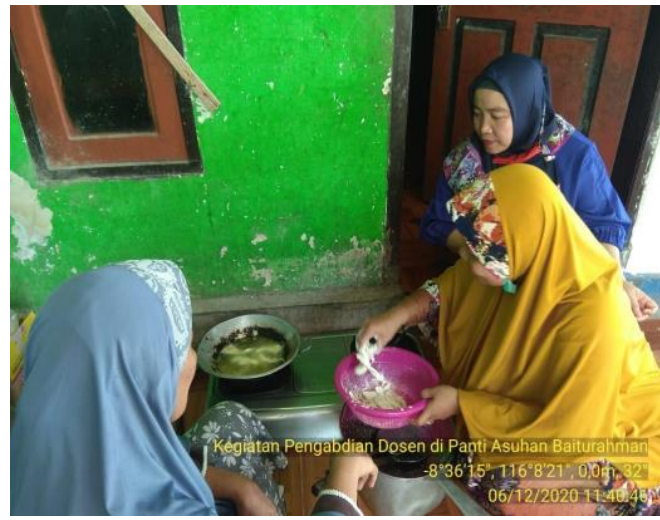

Gambar 6. Proses Penggorengan jamur Crispy

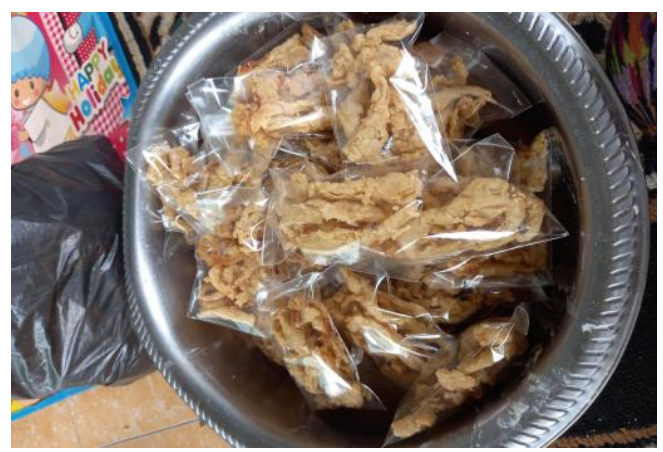

Gambar 7. Hasil dari jamur crispy yang dikemas

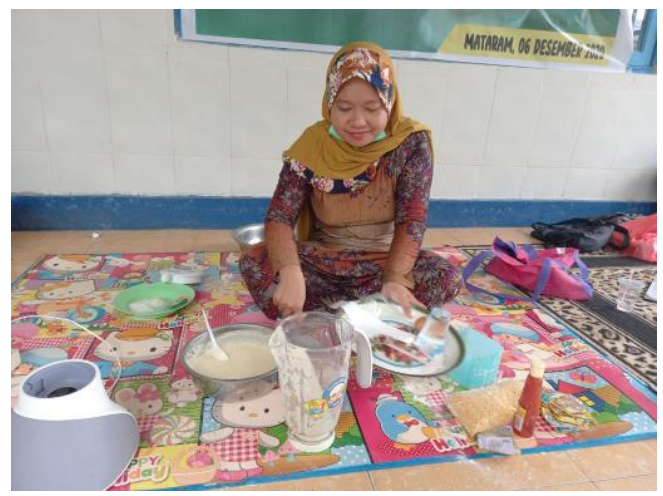

Gambar 8. Pembuatan Nugget jamur

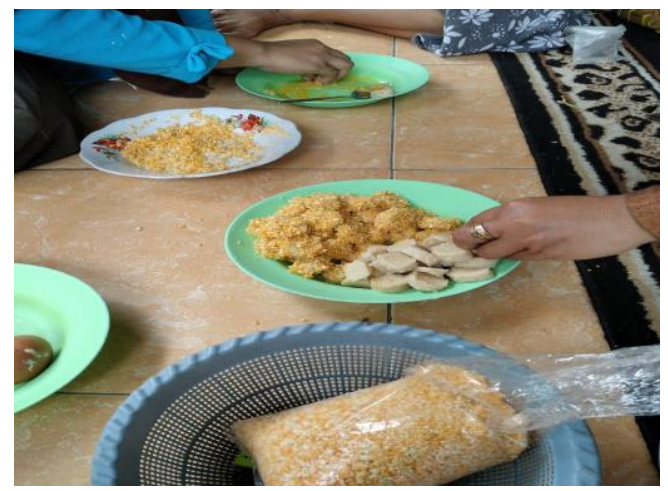

Gambar 9. Proses Pembaluran nugget ke tepung roti

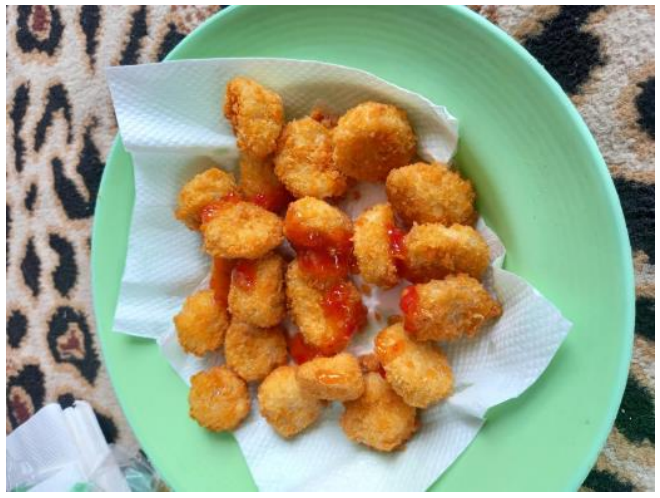

Gambar 10. Nugget Sudah siap saji

Adapun hasil Output yang didapatkan dari kegiatan pengabdian masyarakat adalah:

1. Siswa/siswi diberikan pendidikan tentang peningkatan produksi budidaya jamur tiram dengan perawatan yang baik

2. Dari hasil penyuluhan Siswa/siswi tertarik menekuni usaha jamur tiram

3. Dari hasil praktek langsung Siswa/siswi tertarik menekuni olahan jamur.

\section{Kesimpulan}

Berdasarkan hasil kegiatan dan pembahasan, maka disimpulkan bahwa:

1. Kegiatan pengabdian pada masyarakat di panti asuhan Hidayaturrahman di Desa Turida memberikan pengetahuan dan keterampilan kepada siswa/siswi tentang budidaya dan cara pengolahan jamur tiram menjadi jamur tiram crispy dan nugget sehingga siswa/siswi dapat mengolah jamur tiram secara mandiri.

2. kegiatan pengabdian pada masyarakat ini mendapat respon positif dari siswa/siswi. Hal ini dilihat dari antusiasme siswa/siswi dalam mengikuti kegiatan ini.

3. Dalam rangka meningkatkan pengetahuan dan skill siswa/siswi perlu adanya kegiatan pengabdian lanjutan di panti asuhan Hidayaturrahman.

\section{Daftar Pustaka}

Agustina, W. (2014). Karya Tulis Ilmiah. Budidaya Jamur Tiram, PT Agromedia Pustaka. Yogyakarta.

BPS. (2013). Potensi Pertanian Indonesia.bps.go.id 
Enjo, S. (2015). Budidaya jamur Tiram Media Kardus. PT Agromedia Pustaka. Jakarta Selatan.

Nurul, H., Lilik, S., Elis, N. (2013). Studi Pertumbuhan dan Hasil Produksi Jamur Tiram Putih (Pleurotus ostreatus) Pada Media Tumbuh Jerami Padi dan Serbuk Gergaji. Jurnal Produksi Tanaman. 1(1), hal:47-53.

Retno, D.S., \& Amalia. (2017). Analisis Usahatani Jamur Tiram Putih (Pleurotus Ostreatus) di kelurahan Simpang Baru Kecamatan Tampan Kota Pekanbaru. Jurnal Ilmiah Pertanian 13 (2).

Zulfarina, E.S, Yustina R.A.P., \& Hendra T. (2019). Budidaya Jamur tiram dan Olahan Untuk Kemandirian Masyarakat Desa. Jurnal Pengabdian Masyarakat (Indonesia Journal of Community Engagement), 5 (3), hal:358-370 